\title{
Analysis of Accessibility and Level of Knowledge of Farmers on the Use of ICT among Small Holder Rice Farmers in Southeast, Nigeria
}

\author{
Gbughemobi B.O, Nkamigbo, D.C., Meludu, N.T. \\ Department of Agric Economics and Extension, Faculty of Agriculture, Nnamdi Azikiwe University, \\ Awka, Nigeria, West Africa \\ Corresponding Author: Gbughemobi B.O
}

\begin{abstract}
The study examined Analysis of accessibility and Level of Knowledge of Farmers on the Use of ICT among small holder rice farmers in Southeast, Nigeria. Specifically, it described ICT accessibility and level of knowledge of farmers in the use of ICT and Significant relationship between the farmers' accessibility and knowledge and their level of use of ICT. Data were collected with a well-structured questionnaire from 476 randomly selected rice farmers and were analyzed using a combination of analytical tools such as descriptive statistics, Analysis of variance, correlation and z-test. The information on ICT tools/format accessibility revealed that out of all the accessible ICT tools/format, only Radio set, Television, Mobile Phone, Short Message Services, and On-line Magazines were effectively used. It was discovered that rice farmers have a low knowledge on the use of ICT in their rice farms. Information meant for rice farmers should be tailored to their specific need and more trainings should be organized for rural people on the use of ICT tools/format to help boost their confidence and reliance on ICT gadgets for information were recommended.
\end{abstract}

Keywords: Analysis of accessibility, Level of Knowledge, ICT gadgets, small holder rice farmers, Southeast Nigeria

\section{INTRODUCTION}

Nigeria is one of the sub Saharan African countries of which agriculture was the back bone of her economy before the oil boom of 1970s. Nigeria agriculture is the major source of food and accounts for about $35 \%$ of the Gross Domestic Product (GDP), $37 \%$ of merchandised export, $75 \%$ of the rural household income and $70 \%$ of employment (Ezeano, Ume, Okeke and Gbughemobi (2017). Gbughemobi, Meludu and Nkamigbo (2021) opined that agriculture is the engine of growth for most developing countries of the world and also one of the most effective ways to alleviate poverty and hunger. It can raise income and improve food security for $80 \%$ of the world's poor, who live in rural areas and work mainly in farms. Agriculture in Africa has a massive social and economic footprint; more than $60 \%$ of the populations of Sub-Saharan Africa are smallholder farmers, and about $23 \%$ of Sub-Saharan Gross Domestic Product (GDP) comes from agriculture (Goedde, Ooko-Ombaka and Pais, 2019). Agriculture contributed about $22.86 \%$ of Nigeria's GDP in 2017 (National Bureau of Statistics (NBS), 2018). These smallholder farmers engage in different livestock and crops production including rice.

Nigeria is Africa's largest importer of rice, the current leading consumer of rice and one of the largest producers of rice in Africa; and rice generates more income for Nigerian farmers than any other cash crop in the country (FAO, 2019). Rice is the primary staple food for most of the populace in the region, especially the rural area, with about $6 \%$ of global rice consumption, Africa 
accounts for about $4 \%$ of the world production making the continent the second largest consuming region (Abdul-Gafar, 2016). According to Uba (2003), about $70 \%$ of Nigeria feeds on rice, while $30 \%$ of their cereal-based diets are also from rice. According to Udemezue (2018), Nigerians consume 8 million tonnes of rice and the figure rises by $6 \%$ annually. Programs, projects, and technologies like Value Addition and Information Communication Technologies (ICTs) have been introduced in rice production and agricultural sector to enhance farmers' agricultural production.

$$
\text { Information Communication }
$$

Technology (ICT) can be broadly described as the means through which information can be communicated for individual, societal and collective growth of a nation (Ogunyemi, 2010). Information and Communication Technologies (ICTs) are becoming more and more important in connecting farmers and providing information. ICTs help keep young people involved in agriculture.

ICTs are used to champion practical, cost-effective, and scalable solutions that impact lives. ICTs have a high potential to transform agriculture. They are "means" rather than the "ends". Information and communication technologies (ICTs) could transform agricultural activities in many parts of the world. ICTs cannot solve every problem, but these tools do promote youth involvement in agriculture by enhancing their opportunities, motivation, and capacities. ICTs contribute to improving youth livelihoods, agricultural modernization and create benefits throughout value chains, especially through increased access to more effective information via many smartphone apps (Spore, 2019). ICTs also help strengthen and develop farmers' organizations, especially through social networks. Access to information holds the key to successful agricultural development. Information Communication Technologies (ICTs) in recent years have witnessed major changes and are diverging as a powerful tool for accelerating agricultural growth in a developing country like Nigeria (Enwelu, Uramah, Asadu, and Chan 2014). The introduction of ICTs helps in agricultural farmer's access to market information and services, management of pest and diseases and rural development programs (Meera, Jhamtani and Roa, 2004). It will also help in broadening the orientation of farmers in production activities thereby causing a major turnaround in the agricultural sector as it is doing many in other sectors (Ajayi, Alabi and Akinsola, 2013).

Access refers to the ways and means in which individuals, communities, and institutions are exposed to the use of ICT. It takes into consideration such elements as affordability and availability of the technologies. The geographical location of the access point and the times at which the technologies are available (Ekeanya, Omike, Ifenkwe and Apu, 2017) Ozor and Madukwe (2009) asserted that providing farmers with a variety of information sources, which are accessible, affordable, relevant and reliable is the ultimate aim of providing agricultural information service. These information sources must be communicated to the relevant users farmers.

The role of ICT to enhance food security and support rural livelihood is increasingly recognized and was officially endorsed at the World Summit on the Information Society (WSIS) in 2005. These include the use of computers, the internet, Geographical Information Systems (GIS), mobile phones, as well as traditional media such as radio and television. Although it is a relatively new phenomenon, evidence of the contribution of ICT to agricultural development and poverty alleviation is becoming increasingly available. The introduction of various relevant ICTs in agricultural information dissemination could help farmer's access market information; land resources and services; management of pests and diseases; rural development programs (Meera et al, 2004). It will also help in broadening the orientation of 
farmers in production activities thereby causing a major turnaround in the agricultural sector as it is doing in many other sectors. In Nigeria, policy on the adoption of ICTs was initiated in the year 1999 when the civilian regime came into power (Posa, 2006).

ICTs have a vital role to play in getting information to farmers but many rural communities still have little or no access to it. ICTs have a transformation influence on farming and food production in countries where governments and policymakers are committed to developing comprehensive e-agricultural strategies.

However, given the urgent need for current, reliable, and accurate agricultural knowledge, and in function upon which agricultural policies could be based on sustainable rural agricultural development, many initiatives are warranted, such as training of youths on ICTs (especially in rural areas) and competition on ICT uses in agriculture. Therefore, to benefit the rural people, extensionists are grappling with the issues of how to harness ICTs to improve rural livelihoods to contribute toward better information exchange and access. It is against this background that this study was set out to investigate the knowledge, access and use of ICT among rice farmers in the southeast, Nigeria.

\section{MATERIALS AND METHODS}

The study was conducted in Southeast Nigeria. The population of the study consists of all the rice farmers in Southeastern Nigeria. The zone comprises of Imo, Anambra, Abia, Enugu and Ebonyi States. The region is located between latitude $5^{\circ} 45^{\prime} 00^{\prime \prime} \mathrm{N}$ and longitude $8^{\circ} 30^{\prime} 00^{\prime \prime} \mathrm{E}$. It is bordered by the Niger River in the west with the total surface area of approximately 76000 square kilometers $(29,400 \mathrm{sqkm})$. The region has three types of vegetation. The coastal area in the south is dominated by mangrove swamps and tidal waterways.

Anambra State is located in the South-Eastern part of the country, and comprises 21 Local Government and four agricultural zones to aid planning and rural development. The climate is typically equatorial with two main seasons, the dry and the rainy seasons. It is known for production and marketing of several raw materials and agro products in different parts of the state. Some of the crops produce and marketed in the state include oil palm, maize, rice, yam, groundnut, cassava, garri, cucumber, watermelon, melon, potato, greenbeans (akidi), pigeon pea, soyabean and livestock such as fish, goat, sheep, poultry and cattle are also raised (Nkamigbo, Ugwumba and Okeke,2019). It is an agrarian state with high crop production and marketing activities. Majority of the people are subsistence farmers. It is situated on a generally low elevation on the eastern side of the river Niger, sharing boundaries with Delta State to the west Imo, Abia and Rivers States to the south, Enugu state to the East and Kogi State to the North. The state occupies an area of about $4,844 \mathrm{~km}^{2}$. Geographically, the state lies within longitude $5^{0} 55^{1}$ and $6^{0} 42^{1} \mathrm{~N}$. The population of the state is $4,182,232$ with 863 sqkm density (NPC,2006). The annual rainfall ranges from $1400 \mathrm{~mm}$ in the North to $2500 \mathrm{~mm}$ in the South with temperature of $25^{\circ} \mathrm{C}-35^{\circ} \mathrm{C}$.

Ebonyi State is made up of 13 L.G.As with $5533 \mathrm{~km}^{2}$ as the total landmass and estimated population of 2198371 (NPC 2006). The occupation of the people is predominantly farming with over 80 percent of the population living in rural area and is involved in agricultural production. The vegetation lies between the Rain Forest and Guinea Savannah of Nigeria.

Enugu State is located between latitude $6.5\left(6^{0} 30^{\prime} 0 \mathrm{~N}\right)$ and longitude of 7.5 $\left(7^{0} 30^{\prime} 0 \mathrm{E}\right)$. The state occupies an area of about $8,022,950 \mathrm{KM}^{2}$ (Ezike, 1998) and has a population of about 3,257,278 (NPC, 2006). The state has seventeen (17) Local Government Areas (LGA) and is divided into six (6) agricultural zones namely: Agbani, Awgu, Enugu, Enugu-Ezike, Udi and Nsukka. 


\section{Sampling Technique and sample size}

A multi-stage sampling technique was adopted for this study to select 480 respondents among states in Southeast, Nigeria.

Stage 1: This involved purposive selection of three states with a high concentration of rice farmers in Southeast, Nigeria; (Anambra, Enugu and Ebonyi State).

Stage 2: Purposive selection of two (2) agricultural zones from each State making it a total of six (6) zones

Stage 3: Purposive selection of two (2) Local governments from each of the agricultural zones based on high concentration of rice farmers making it a total of twelve (12) local governments

Stage 4: Random selection of two (2) communities from each local government making it a total of twenty-four (24) communities

Finally, twenty (20) rice farmers were selected from each community using the simple random sampling technique. This gave a total sample of four hundred and eighty (480) respondents.

\section{Method of Data collection and Analysis}

Qualitative and quantitative methods were used to collect data from the respondents. Qualitative data were collected using focus group discussion (FGD). The researcher employed the use of Survey CTO which is a powerful, reliable and easy to use survey platform that allows one to at least transport and process data for academic research. Data were analyzed using descriptive analysis such as mean, frequency and percentage, Tobit regression model and inferential statistics (Analysis of variance, Spearman bivariate correlation, and Z-test).

\section{Measurement of variables}

Sex: $\quad$ Sex $($ dummy, male $=1$, female $=0)$

Age: Measured in years.

Marital status: single $=1$, married $=2$, widow $(\mathrm{er})=3$, separated $=4$

Educational qualification: Number of years spent in School

Farming experience $=$ Years
Farm size (Ha)

Household size

Primary occupation

Annual income = $(\#)$

Membership of a corporative

The level of knowledge of ICT: farmers were asked to tick yes or no to assess their knowledge from the list of statements about ICT. The respondents were allowed multiple responses as they may have more than one knowledge of the subject under discussion. Based on the rule of thumb, level of knowledge is categorized into three as low knowledge with a value of 2, medium knowledge with a value of 4 , and high knowledge with a value of 6 . A ratio representation of these indicates that variables with percentage value less than $33.3 \%$ is low knowledge, while $33.3 \%$ to less than $50.0 \%$ is medium knowledge, and high knowledge ranges from $50.0 \%$ and above.

Attitude of the farmers The farmers were asked to rate their feelings on ICT, on a 5point Likert scale of strongly agree (5) agree (4) somewhat agree (3) disagree (2) strongly disagree (1)

Available ICT for use the respondents were asked to tick from the list of the available ICT provided. The respondents were allowed multiple responses as more than one ICT tools/ format maybe available to them.

Level of access to ICT the farmers were asked to rate their access to available ICT on a 5-point Likert scale. The Likert scale and their corresponding values include highly accessible $=5$; accessible $=4$, moderately accessible $=3$, barely accessible $=2$ and strongly not accessible $=1$. The values will be added to get 15 , which will be divided by 5 to get a mean score of 3.Variables with a mean score of 3 and above will be regarded as accessible while variables with a mean score less than 3 were regarded as not accessible.

Challenges faced by farmers on the use of ICT: 5- point Likert scale, with 
options of very serious $=5$; serious $=4$; somewhat serious $=3$; not serious $=2$; not a problem $=1$. The farmer's rating was subjected to a principal factor analysis (PFA) matrix to ascertain the factor loading.

Level of usage of ICT by the farmers. The farmers were asked to rate their extent of use of ICT available to them on a 5-point Likert scale of very often $=5$; often $=4$; moderate $=3$; rarely $=2$ and never used $=1$. The values were added to get 15 and divided by 5 to get the mean value of 3 Any variable with a mean score 3 and above was regarded as being used frequently by farmers while variable with a mean score of less than 2 was regarded as not being used frequently.

\section{RESULT AND DISCUSSION ICT Accessibility}

The ICT accessibility in the study area is presented in Table 1 . The information was subjected to a 5 Point Likert Scale to determine the mean threshold of ICT tools/format accessibility. The mean threshold of less than 3.0 was not accessible, while the mean threshold of 3.0 and above was said to be accessible to the farmers. Thus, based on the 24 items of ICT tools/format accessibility captured, only 6 had a mean threshold of 3.0 and are; Radio set, Television, Facebook, Mobile Phone, Short Message Services and Whatsapp. The cluster mean of 2.54 shows that the majority of the ICT tools/format were not accessible, while the standard deviation of 1.01 shows that their individual responses varied enough to make logical conclusions. This is expected since the ICT tools were scarcely available in the study area. The finding agrees with (Enwelu et al, 2014) who discovered that farmers had low access to modern ICT tools.

Table 1: Distribution of ICT Accessibility in the Study Area

\begin{tabular}{|c|c|c|c|c|c|c|c|c|c|}
\hline $\mathbf{S} / \mathbf{n}$. & Tools & SNA & $\mathbf{B A}$ & MA & $\mathbf{A}$ & SA & Mean & Std. Dev. & Decision \\
\hline 1. & Radio set & 0 & 11 & 113 & 207 & 145 & 4.66 & 0.51 & Accessible \\
\hline 2. & Television & 51 & 117 & 93 & 144 & 71 & 4.02 & 0.80 & Accessible \\
\hline 3. & Facebook & 24 & 0 & 8 & 261 & 183 & 3.14 & 1.25 & Accessible \\
\hline 4. & Mobile Phone & 11 & 71 & 253 & 81 & 60 & 4.27 & 0.73 & Accessible \\
\hline 5. & Short Message Services & 79 & 249 & 40 & 74 & 34 & 3.23 & 0.93 & Accessible \\
\hline 6. & CD-ROM & 95 & 214 & 11 & 122 & 34 & 2.44 & 1.15 & Not accessible \\
\hline 7. & Video CD Player & 62 & 170 & 78 & 91 & 75 & 2.55 & 1.26 & Not accessible \\
\hline 8. & Computer System & 59 & 168 & 91 & 83 & 75 & 2.89 & 1.30 & Not accessible \\
\hline 9. & Internet & 126 & 267 & 34 & 22 & 27 & 2.89 & 1.28 & Not accessible \\
\hline 10. & Digital Camera & 151 & 173 & 33 & 99 & 20 & 2.07 & 1.01 & Not accessible \\
\hline 11. & YouTube & 219 & 180 & 14 & 43 & 20 & 2.29 & 1.23 & Not accessible \\
\hline 12. & Multimedia Projector & 163 & 176 & 48 & 62 & 27 & 1.88 & 1.10 & Not accessible \\
\hline 13. & Digital video Disk (DVD) & 104 & 122 & 79 & 122 & 49 & 2.19 & 1.20 & Not accessible \\
\hline 14. & E-mail & 222 & 152 & 56 & 46 & 0 & 2.77 & 1.32 & Not accessible \\
\hline 15. & On-line Magazines & 121 & 299 & 28 & 28 & 0 & 1.84 & 0.97 & Not accessible \\
\hline 16. & GPRS & 40 & 97 & 36 & 212 & 91 & 1.92 & 0.74 & Not accessible \\
\hline 17. & Whatsapp & 59 & 192 & 98 & 71 & 56 & 3.46 & 1.24 & Accessible \\
\hline 18. & Instagram & 203 & 213 & 19 & 41 & 0 & 2.73 & 1.20 & Not accessible \\
\hline 19. & Video Conferencing & 293 & 143 & 26 & 14 & 0 & 1.79 & 0.88 & Not accessible \\
\hline 20. & Tele Conferencing & 332 & 138 & 6 & 0 & 0 & 1.5 & 0.73 & Not accessible \\
\hline 21. & Robots & 332 & 138 & 6 & 0 & 0 & 1.33 & 0.55 & Not accessible \\
\hline 22. & Twitter & 217 & 126 & 32 & 46 & 55 & 2.15 & 1.39 & Not accessible \\
\hline 23. & Likee (Online Video posting) & 117 & 26 & 27 & 0 & 0 & 1.53 & 0.84 & Not accessible \\
\hline \multirow[t]{2}{*}{24.} & Mixler (Online Radio) & 318 & 118 & 33 & 7 & 0 & 1.43 & 0.69 & Not accessible \\
\hline & Cluster mean & & & & & & 2.54 & 1.01 & Not accessible \\
\hline
\end{tabular}

\section{Level of Knowledge of Farmers on the Use of ICT}

The farmer's knowledge of information and communication technology (ICT) is presented in Table 2. The respondent's knowledge is descriptively presented and ranked using multiple responses format, the Table shows that first five knowledge definition as identified by the farmers were; ICT are technologies that facilitates communication, processing and transmission of information by electronic 
means, ICTs are communication hardware adopted in ensuring instant dissemination of information, ICT includes a range of rapidly evolving technologies and they include telecommunication technologies, ICT consists of hardware, software telecommunication networks, work status and robotics as well as smart chips used in collecting, processing, storage and transmission of information by electronic means, and ICTs are electronic devices for capturing, processing storage and communicating information. The order of their percentage representation is $80.0 \%$, $24.8 \%, 21.0 \%, 20.2 \%$ and $13.9 \%$. Summarily, the respondents have a low knowledge on the use of ICT in their rice farms. This is in line with the findings of (Ajayi, Alaba, Okanlawon, 2018) that farmers have low knowledge on the use of information and communication technology.

Table 2: Distribution of Knowledge of Farmers on the Use of ICT in the Study Area

\begin{tabular}{|c|l|c|c|c|}
\hline Sn. & \multicolumn{1}{|c|}{ ICT Tools/formats } & Preq. & Per. & Ranking \\
\hline 1. & ICTs are communication hardware adopted in ensuring instant dissemination of information & 118 & 24.8 & 2 \\
\hline 2. & ICT includes a range of rapidly evolving technologies and they include telecommunication technologies & 100 & 21.0 & 3 \\
\hline 3. & $\begin{array}{l}\text { ICT consists of hardware, software telecommunication networks, work status and robotics as well as } \\
\text { smart chips used in collecting, processing, storage and transmission of information by electronic means }\end{array}$ & 96 & 20.2 & 4 \\
\hline 4. & $\begin{array}{l}\text { ICT are technologies that facilitates communication, processing and transmission of information by } \\
\text { electronic means }\end{array}$ & 381 & 80.0 & 1 \\
\hline 5. & ICTs are electronic devices for capturing, processing storage and communicating information & 66 & 13.9 & 5 \\
\hline 6. & $\begin{array}{l}\text { ICT are means through which information can be communicated for individual, societal and collective } \\
\text { growth of a nation }\end{array}$ & 58 & 12.2 & 6 \\
\hline
\end{tabular}

Source: Field Survey Data, 2020. *Multiple Response

\section{Level of Knowledge of Farmers on the Use of ICT}

Majority (78.2\%) have low knowledge of ICT, while others have medium knowledge (20.4\%) and high knowledge (1.5\%). The mean knowledge of
28.9 falls within low knowledge which justifies that ICT has a low or weak knowledge among the farmers. Equally, the standard deviation of 20.44 is high enough to show the variability of their responses for decision making.

Table 2.2: Distribution of Knowledge of Farmers on the Use of ICT

\begin{tabular}{|c|c|c|c|c|c|c|}
\hline Possible score & Observed score & Classification & Frequency & Percentage & Mean & Std. dev \\
\hline $0-100$ & $17-100$ & Low (up to 49) & 372 & 78.2 & & \\
\hline & & Medium (50-69) & 97 & 20.4 & 28.9 & 20.44 \\
\hline & High (above 69) & 7 & 1.5 & & \\
\hline & Total & $\mathbf{4 7 6}$ & $\mathbf{1 0 0}$ & & \\
\hline & & \multicolumn{7}{c|}{ Source: Field Survey Data, 2020. }
\end{tabular}

Significant relationship between the farmers' accessibility and their level of use of ICT

The result of hypothesis on the relationship between the farmer's ICT accessibility and level of use of ICT tools/format is in Table 3. The spearman Bivariate correlation for non-parametric tool conducted to test the significant correlation between the level of use of ICT tools/format and accessibility in the study area was positive and significant at two tailed probability level of 0.01 . This implies that a unit increase in the accessibility of ICT tools/format will positively increase its (ICT tools/format) level of use in the area by 0.826 units. Thus, the null hypothesis three was rejected. This result is in conformity with the results obtained by (Raghuprasad, Devaraj \& Gopala,2012)

Table 3: Significant relationship between the farmers' accessibility and their level of use of ICT $(n=476)$

\begin{tabular}{|c|l|l|c|c|}
\hline \multicolumn{3}{|c|}{ Correlations } & Use & Accessibility \\
\hline \multirow{3}{*}{ Spearman's rho } & \multirow{3}{*}{ Use } & Correlation Coefficient & 1.000 & $0.826^{* *}$ \\
\cline { 3 - 5 } & & Sig. (2-tailed) &. & 0.000 \\
\cline { 3 - 5 } & $\mathrm{N}$ & 476 & 476 \\
\cline { 3 - 5 } & Accessibility & Correlation Coefficient & $0.826^{* *}$ & 1.000 \\
\cline { 3 - 5 } & & Sig. (2-tailed) & 0.000 &. \\
\cline { 3 - 5 } & $\mathrm{N}$ & 476 & 476 \\
\hline & & & \\
\hline
\end{tabular}

Source: Field Survey Data, 2020. Bivariate correlation matrix 


\section{Significant relationship between Farmers' knowledge and their level of use of ICT}

The result of hypothesis on the influence of farmer's knowledge on the use of ICT tools/format is in Table 4. The result on the influence of knowledge on use of ICT tolls/format had a sum square between group and within group of 105.32484 and 181.3182 respectively. The total degree of freedom was 475. The F-stat. value of $60.40 * * *$ is highly significant at probability level of $1 \%$. This significant F-distribution shows the normality of the variables. Thus, the null hypothesis four was rejected and the alternate accepted that knowledge influence the use of ICT tools/format. This agrees with the findings of John and Barclay (2017).

Table 4: Significant relationship between Farmers' knowledge and their level of use of ICT $(n=476)$

\begin{tabular}{|c|c|c|c|c|c|}
\hline Source & Sum Square & Degree of freedom & Mean square & F-stat. & Prob>F \\
\hline Between knowledge & 105.32484 & 4 & 26.33121 & $68.40^{* * *}$ & 0.000 \\
\hline Within knowledge & 181.3182 & 471 & 0.38495502 & & \\
\hline Total & $\mathbf{2 8 6 . 2 3 5 6 0}$ & $\mathbf{4 7 5}$ & $\mathbf{0 . 6 0 3 4 4 9 8}$ & & \\
\hline
\end{tabular}

Source: Field Survey Data, 2020. One-way ANOVA. F-stat. at 1.96 (prob> 0.05)

\section{SUMMARY AND CONCLUSION}

The study examined the analysis of accessibility and Level of Knowledge of Farmers on the Use of ICT among small holder rice farmers in Southeast, Nigeria. Data were collected with a well-structured questionnaire from 476 randomly selected rice farmers and were analyzed using a combination of analytical tools such as descriptive statistics, Analysis of variance, correlation and z-test. The information on ICT tools/format accessibility reveals that Radio set, Television, Facebook, Mobile Phone, Short Message Services and Whatsapp were accessible. Out of all the accessible ICT tools/format, only Radio set, Television, Mobile Phone, Short Message Services, and On-line Magazines were effectively used. The result also revealed a low knowledge on the use of ICT among rice farmers in the South Eastern Nigeria. Information meant for rice farmers should be tailored to their specific need and more trainings should be organized for rural people on the use of ICT tools/format to help boost their confidence and reliance on ICT gadgets for information were recommended.

Acknowledgement: None

Conflict of Interest: None

Source of Funding: None

\section{REFERENCES}

1. Abdul-Gafar, A. (2016). Perceptions of rice farmers towards production constraints: case study of Niger State of Nigeria and Hainan of China. Journal of Agricultural Chemistry and Environment, 5(01), 20.

2. Ajayi A.O., Alabi O.S and Akinsola T.O (2013). Knowledge and perception of extension agents on information and communication technologies (ICTs) Use in extension service delivery in Ondo State Nigeria. African Journal of Agricultural Research, 8 (84),6226-6233

3. Ajayi, A. O., Alabi, O. S., \& Okanlawon, B. I. (2018). Knowledge and perception of farmers on the use of information and communication technology (ICT) in IfeCentral Local Government Area of Osun State: Implications for rural development. Journal of Agricultural Extension and Rural Development, 10(3), 44-53

4. Ekeanya, N. M., Omike, A. I. G. E., Ifenkwe, G. E., \& Apu, U. (2018). Access and Use of Information Communication Technology among Pig Farmers in Orlu Local Government Area Imo State Nigeria. Journal of Agricultural Extension, 22(1), 77-86.

5. Enwelu, I.A, K.O. Uramah, A.M. Asadu and J. Chan (2014) Assessment ICT utilization in Agriculture across gender in Enugu Ezike Agricultural zone of Enugu State, Nigeria. Journal of Agricultural extension, 18 (2),8689.

6. Ezeano, C. I., Ume, S. I., Okeke, C. C., \& Gbughemobi, B. O. (2017). Socioeconomic Determinant Factors to Youths Participation 
in Broilers Production in Imo State of Nigeria. International Journal of Research \& Review, 4(1), 136-142.

7. Ezike, J.O. (1998), Delineation of old and new Enugu State Government Bulletin, Enugu, Ministry of Works

8. Food and Agricultural Organization (2019). FAOSTAT.

https://www.fao.org/faostat/en/\#home.

Accessed date: 9 April, 2020

9. Goedde, L., Ooko-Ombaka, A., \& Pais, G. (2019). Winning in Africa's agricultural market. McKinsey \& Company [accessed 20 April 2020] Available at: https://www. mckinsey. com/industries/agriculture/ourinsights/winning-in-africasagricultural-

market.

10. Gbughemobi,B.O., Meludu, N.T and Nkamigbo, D.C. (2021). Socioeconomic determinants and availability of ICT for use among small holder rice farmers in Southeast, Nigeria. Intl Journal of Environmental and Agriculture Research, (IJOEAR), 7(9),34-40.

11. John, A., \& Barclay, F. P. (2017). ICT usage and effects among rural farming communities. Journal of Media and Communication, 1(1), 100-136.

12. Meera, S.N, Thamtan, A. and Rao, D, U.M (2004). Information and communication technology in agricultural development: A comparative analysis of three projects from India. Agricultural research and extension network paper No. 135 overseas development institute, London

13. National Bureau of Statistics (2018). Nigeria Gross Domestic Product Report. Government of Nigeria, Nigeria.

14. Nkamigbo, D.C, Ugwumba, C.A.O. and Okeke, U., (2019). Market structure, conduct and volume of trade among channels of watermelon marketing in Anambra State, Nigeria. Inter J Agri Biosci, 8(2): 112-116.

15. National Population Commission (NPC, 2006). Provisional Population Census
Report. Abuja, National Bureau of Statistics.

16. Ozor, N., \& Madukwe, M. C. (2009). Role of information communication technology in agricultural development. General Agriculture: Principles and Practices, Faculty of Agriculture, University of Nigeria, Nsukka, 20-24

17. Ogunyemi, O. (2010). Consumption and (in) appropriate use of mobile phone among teenage Africans in the United Kingdom, Lincoln School of Journalism publications https:www.researchgate.net/publication/242 235808,1-22.

18. Posa, M.A. (2006). Information and communication technologies in the Nigerian economy. Paper presented at the International Conference on Human and Economic Resources, Izmir University, Cortlan, December, 2006, pp. 329-337, retrieved on $26^{\text {th }}$ of December, 2013 from http:i/eco.ieu.odu.tr/wpcontent/proceedings/ 2006/0626.pdf.

19. Raghuprasad, K. P., Devaraja, S. C., \& Gopala, Y. M. (2012). Attitude of Farmers towards Utilization of Information Communication Technology (ICT) Tools in Farm Communication. Research Journal of Agricultural Sciences, 3(5), 1035-1037.

20. Uba, G. (2013). Nigeria: Investing in rice production and rice processing project. Thursday, $15^{\text {th }} \quad$ January, 2013. www.thisday.ng. Accessed $4^{\text {th }}$ March, 2020.

21. Udemezue, J. C. (2018). Analysis of rice production and consumption trends in Nigeria. Journal of Plant Science and Crop Protection, 1(3), 305-311.

How to cite this article: Gbughemobi B.O, Nkamigbo, D.C., Meludu, N.T. Analysis of accessibility and level of knowledge of farmers on the use of ICT among small holder rice farmers in Southeast, Nigeria. International Journal of Research and Review. 2021; 8(10): 133-140. DOI: https://doi.org/10.52403/ijrr. 20211018 